\title{
HOW TO PLUG OUT OF THE NETWORKS IN JEOPARDY OF ASF, COVID-19, SOCIAL MEDIA OR MARKETS TOXICITY
}

\author{
ANDRZEJ BudA \\ Interdisciplinary Research Institute \\ ul. Oriona 15/8, 67-200 Glogow, Poland \\ e-mail address: andrzejbuda@wp.pl \\ ORCID: 0000-0002-2492-5580 \\ KatARZYNA KuŹMicZ \\ Interdisciplinary Research Institute \\ ul. Oriona 15/8, 67-200 Glogow, Poland \\ E-mail address: k.kuzmicz8d@gmail.com \\ ORCID: 0000-0003-3776-4402
}

\begin{abstract}
Aim: In our research, we examine universal properties of the global network whose structure represents a real-world network that might be later extended to social media, commodity market or countries under the influence of diseases like Covid-19 or ASF.

Methods: We propose quasi-epidemiological agent-based model of virus spread on a network. Firstly, we consider countries represented by subnetworks that have a scale-free structure achieved by the preferential attachment construction with a node hierarchy and binary edges. The global network of countries is a complete, directed, weighted network of these subnetworks connected by their capitals and divided into cultural and geographical proximity. Viruses with a defined strength or aggressiveness occur independently at one of the nodes of a selected subnetwork and correspond to a piece of products or messages or diseases.

Results and conclusion: We analyse dynamics set by varying parameter values and observe a variety of phenomena including local and global pandemics and the existence of an epidemic threshold in the subnetworks. These phenomena have been also shown from individual users points of view because the node removal from the network might have impact on its nearest neighbours differently. The selective participation in global network is proposed here to avoid side effects when the global network has been fully connected and no longer divided into clusters.
\end{abstract}

Keywords: Epidemic spreading, social networks, complex networks, agent-based models

\section{INTRODUCTION AND MOTIVATION}

Since January 2020, Covid-19 has affected human activity in crucial areas. This local contagious disease SARS-CoV-2 that might have leaked from a Wuhan laboratory (Nature, 2021) and became global, has a tropism for ACE2-expressing epi- 
thelial cells of the respiratory tract. People with severe COVID-19 have symptoms of systemic hyperinflammation. Clinical laboratory findings of elevated IL-2, IL-7, IL-6, granulocyte-macrophage colony-stimulating factor (GM-CSF), interferon gamma-induced protein10 (IP-10), monocyte chemoattractant protein-1 (MCP1), macrophage inflammatory protein 1-alpha (MIP-1-alpha), and tumour necrosis factor (TNF- $\alpha$ ) indicative of cytokine release syndrome (CRS) suggest an underlying immunopathology (Huang 2020,). Moreover, the severity of the inflammation can be attributed to the severity of what is known as the cytokine storm in which the innate immune system causes an uncontrolled and excessive release of proinflammatory signaling molecules called cytokines.

The viral nature of Covid-19 has overtaken the global economy and social media as well because most countries decided to react without complete knowledge and introduce lockdowns depending on virus activity only. Therefore stock markets that belong to complex networks (Kwapień, 2012) and depend on delivery chains or production have started to collapse because of toxic assets. On the other hand, we have observed coronapanic in social media and fake news. This phenomena has been previously investigated well in case of ASF (Buda, Jarynowski, 2020). However, human activity has become limited to the Internet area because of pandemic restrictions, online shopping and education. The universal properties of these kinds of activities has been also discussed and examined (Buda, 2020).

The reason behind these phenomena never known before is a topological structure of networks that determine human activity and connect people from all over the world. Therefore we have decided to apply a quasi-epidemiological model of virus spread on scale free network which is universal and may be extended to real networks and individual users point of view. Agent-based modelling often used by statistical physicists (Epstein, 1999; Samanidou, 2007; Chakraborti, 2011) has supplied a huge boost to analyse large systems in economy, social science and epidemiology. There have been a lot of possible topological settings considered in epidemiological contexts: square lattices (Sadedin 2003,; Dybiec 2009), completely connected networks with possible direct virus transmission between any pair of agents (Kephart, 1991; Trpevski, 2011), Markovian networks with correlated connectivity of neighbouring nodes (Boguna, 2002), small-world networks with high clustering (Trpevski, 2011; Edoh, 2018), Erdos-Renyi networks with high homogeneity of interactions (Trpevski, 2011; Reppas, 2012; Edoh, 2018) and scale-free networks with a power-law distribution of node connectivity (Pastor-Sattoras, 2001; Moreno, 2002). Setting the modelled dynamics in a scale-free network allows us to apply a variety of factors within a simple structure.

\section{METHODS AND RESULTS}

According to knowledge given in the previous section, it is reasonable to investigate properties of the global network from an Agent-Based Modeling point of view. Therefore, the global network may be described by conditions based on epidemiology: 
1. The global network contains 100 subnetworks that represent local countries (their size is randomised from uniform distribution expressed in logarithmic scale);

2. Each subnetwork has a Barabasi-Albert network structure with binary edges. Capitals in these subnetworks are defined by nodes with the highest connectivity;

3. All the 100 national subnetworks are connected by their capitals only. The weight of connections between capitals $w_{i j}$ is chosen randomly from normal distribution (and represents cultural connections between countries);

4. Each product (virus) has different attractiveness expressed by the parameter $a$ that belongs to $[0,1]$;

5. The initial node for each virus life-cycle is chosen randomly from the entire global network;

6. In the next consecutive step, the product (virus) might be contagious to nearest neighbour $j$ with the probability:

$$
p_{j}(a)=\frac{a}{c_{j}}
$$

where $c_{j}$ is the connectivity of node $j$.

7. Whenever the virus on the national subnetwork comes to the capital node $i$, the popularity is exported to all other capitals $j$ as well, according to formula:

$$
p_{j}(a)=w_{i j} \frac{a}{c_{j}}
$$

where $w_{i j}$ represents the weight of cultural connection between capitals $i$ and $j$, chosen randomly from normal distribution (and represents cultural connections between countries).

8. For all the contagious nodes, it is possible to introduce additional external parameter $v$ (natural number) that represents time of being contagious in other steps of simulation.

From epidemic or commodity markets point of view, typical value of $v=2$ (two weeks). In the first week, customers adopt virus from the retailer. In the second week, customers are affected and share their opinion or virus with the nearest neighbours who also become customers in the next step and so on. Such a stream (direct marketing) has the highest credibility (Stark, 2004) and does not involve any additional promotion or national lockdowns.

In our model, we have investigated how the number of successful realisations [\%] depends on attractiveness of a virus (Fig. 1). The realisation is defined as 'successful' if the country still has infected nodes in next consecutive steps of simulation when $t>v$. For each $a$ we have created variety of 100 worlds (global networks) and checked whenever $a$ song successfully affected local or global phonographic market. This simulation has been done thrice for each set of various investigated parameters (in different, randomly created global phonographic market networks). 


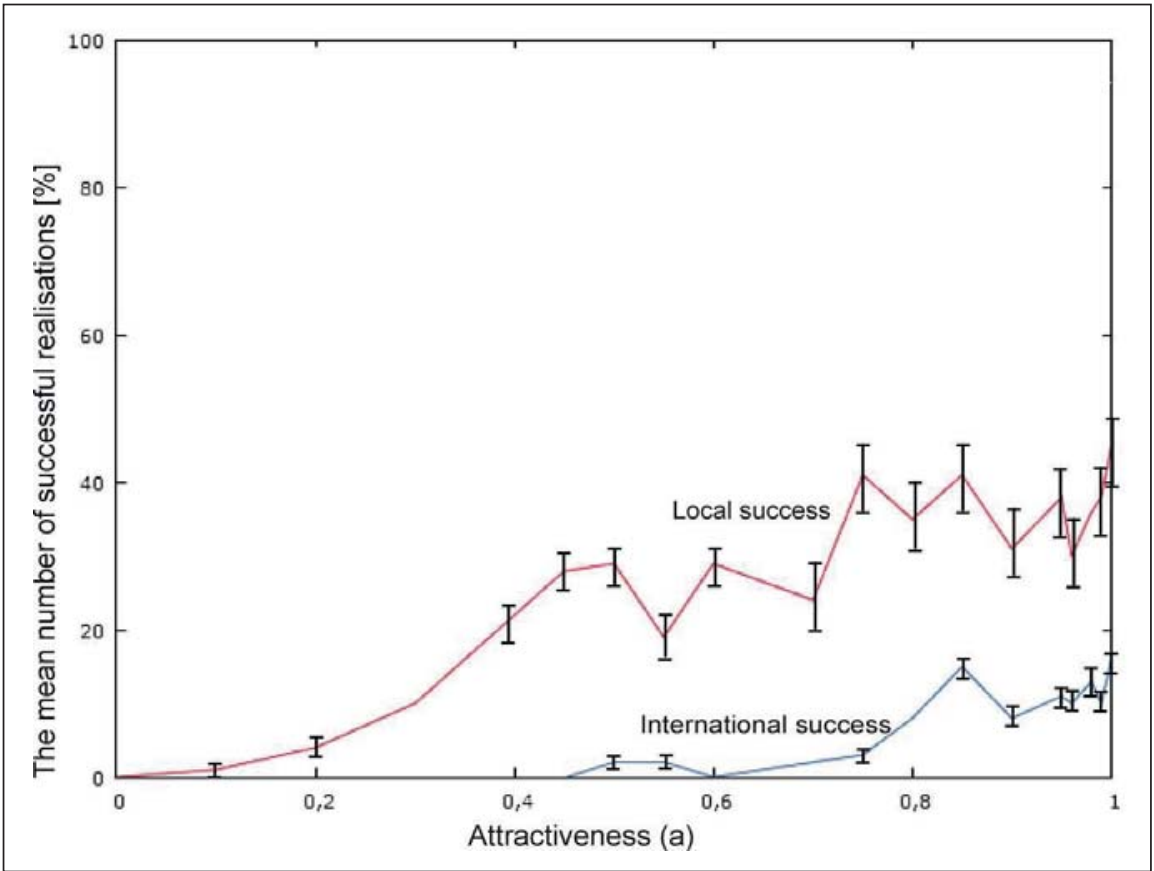

Fig. 1. The mean number of successful realisations [\%] that depends on attractiveness $a$ (when $v=2$ ) in local (upper line) and global (international) networks. Boxplots represent standard deviations.

Source: own research.

According to our results, the number (percentage) of successful realisation increases with attractiveness $a$. However, the local success seems to be elusive when $a<0.4$. Even if $a=0.99$, the number of successful realisations is $38 / 100$ in local countries and 9/100 in the global network.

We have also investigated the average number of infected nodes in consecutive steps of simulation (Fig. 2) that might reflect the virus life-cycle in commodity markets, or social networks. However, in our model the global network consists of local Barabasi-Albert subnetworks. Thus, the virus life-cycle (Fig. 2) might be irregular as a superposition of various life-cycles in local national markets. Our model is consistent with empirical data, where seasonal epidemies or the popularity of international products like songs and movies approximately lasts for half a year.

In the real world data, even the most popular diseases don't affect the entire world because of variety and limited number of potential vectors. The spatial stages of virus life-cycle (Fig. 4) include black or grey colours proportional to the degree of infection inside local countries (defined as a percentage of infected nodes in considered step of simulation $t$ ). 


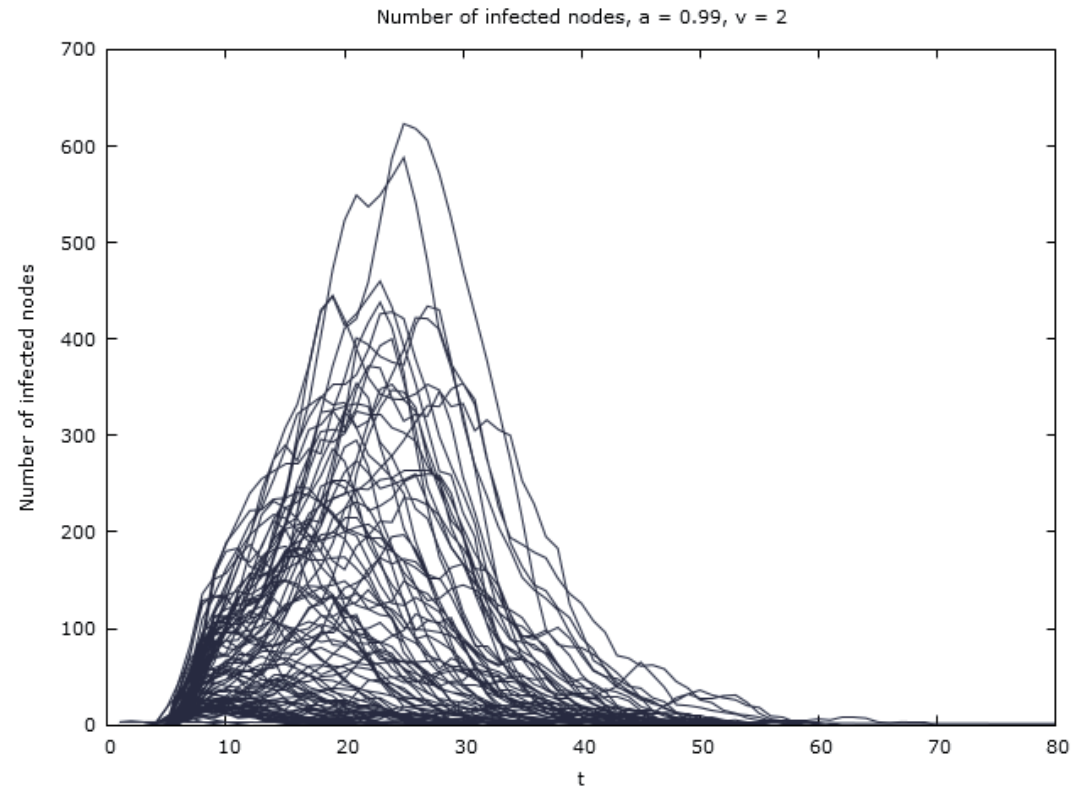

Fig. 2. Whenever the realisation is internationally successful, typical virus lifecycle is a bunch of 100 trajectories $(a=0.99, v=2)$

Source: own research.

Fig. 3. An example of different stages of pandemic behaviour (in different consecutive steps $t$ ) in the global network. The intensity of black/grey colors reflects the percentage of infected nodes within countries $(a=0.99, v=2)$. Source: own research.
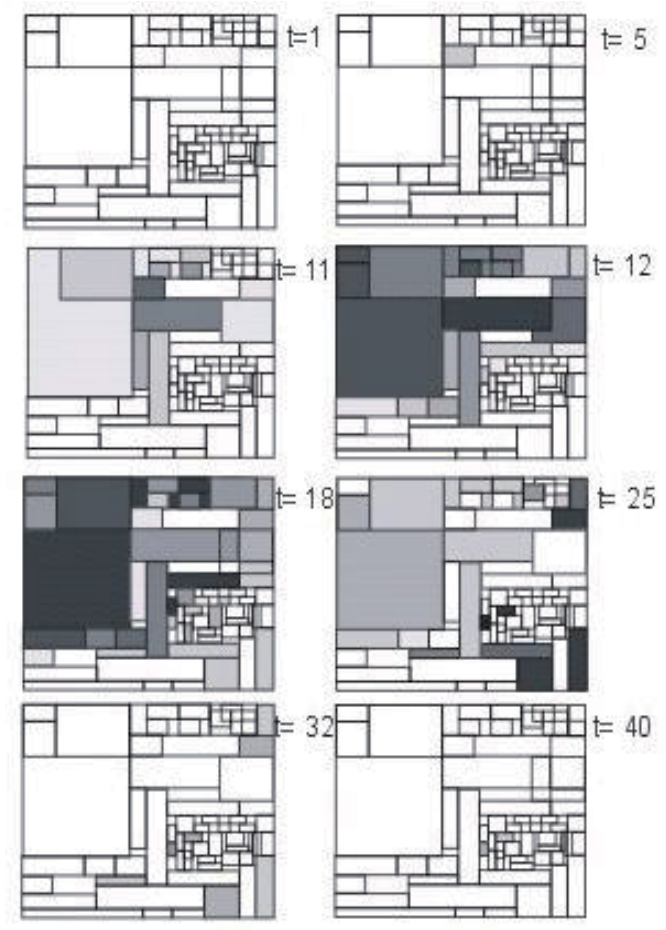


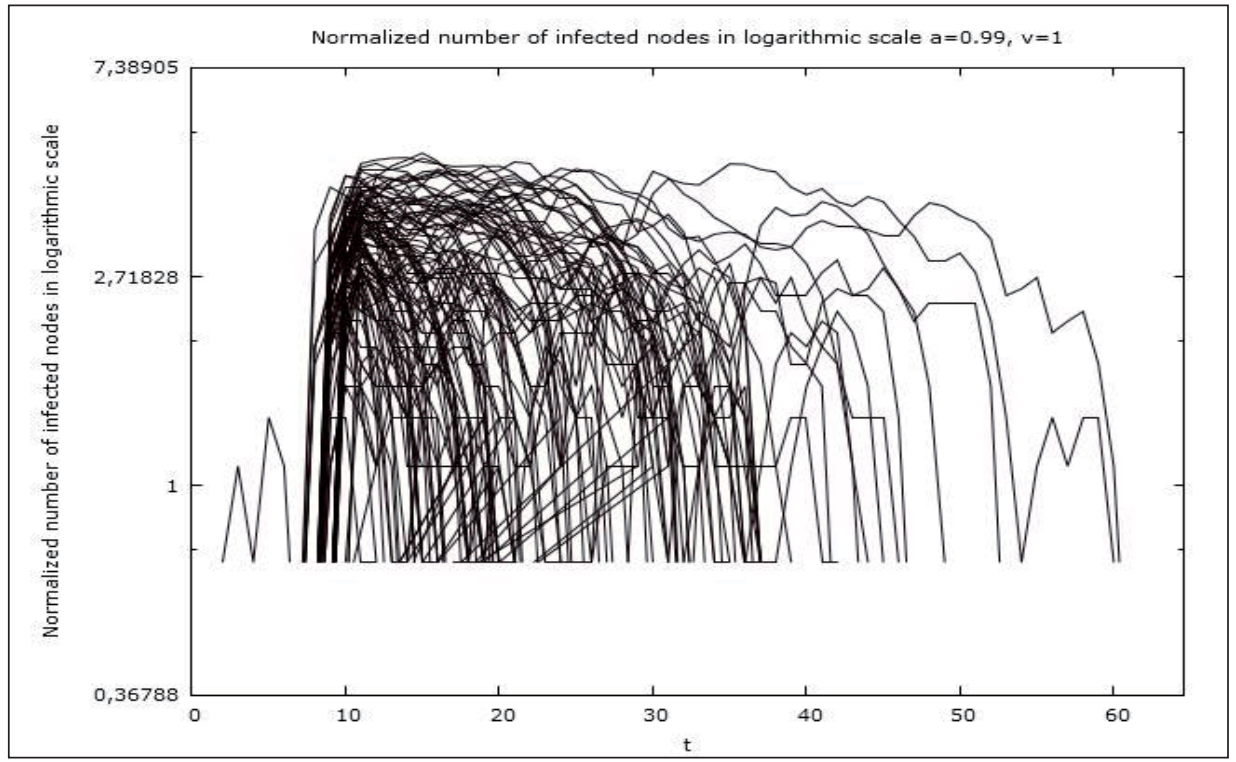

Fig. 4a. Trajectories of attractive virus life-cycle performed in 100 local networks Source: own research.

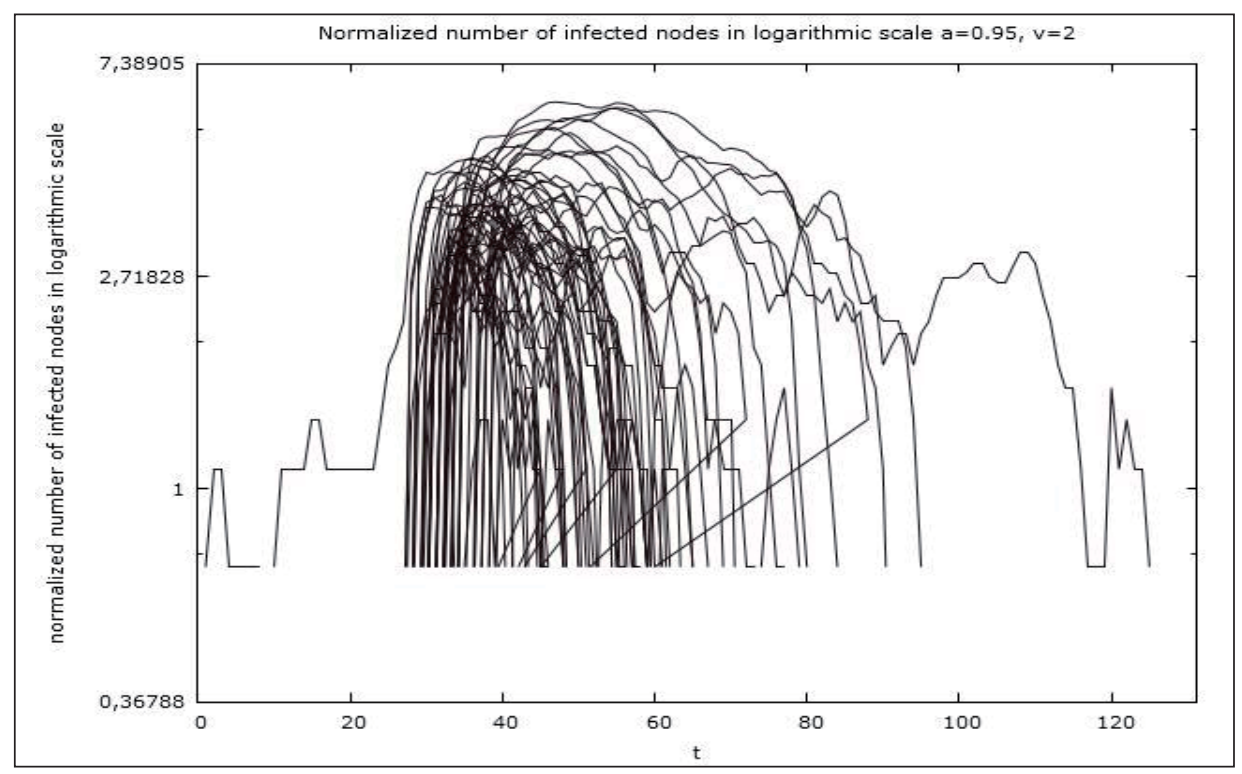

Fig. $4 b$ Trajectories of attractive virus life-cycle performed in 100 local networks Source: own research. 


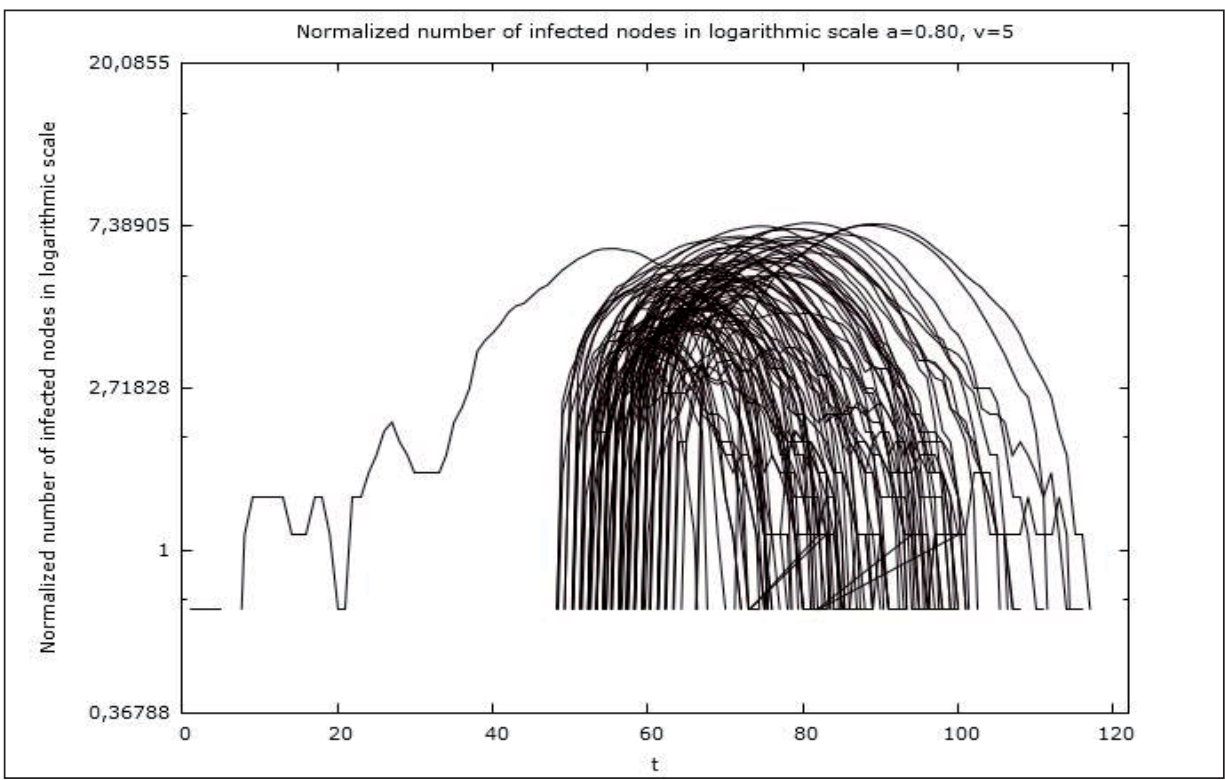

Fig. 4c. Trajectories of attractive virus life-cycle performed in 100 local networks Source: own research.

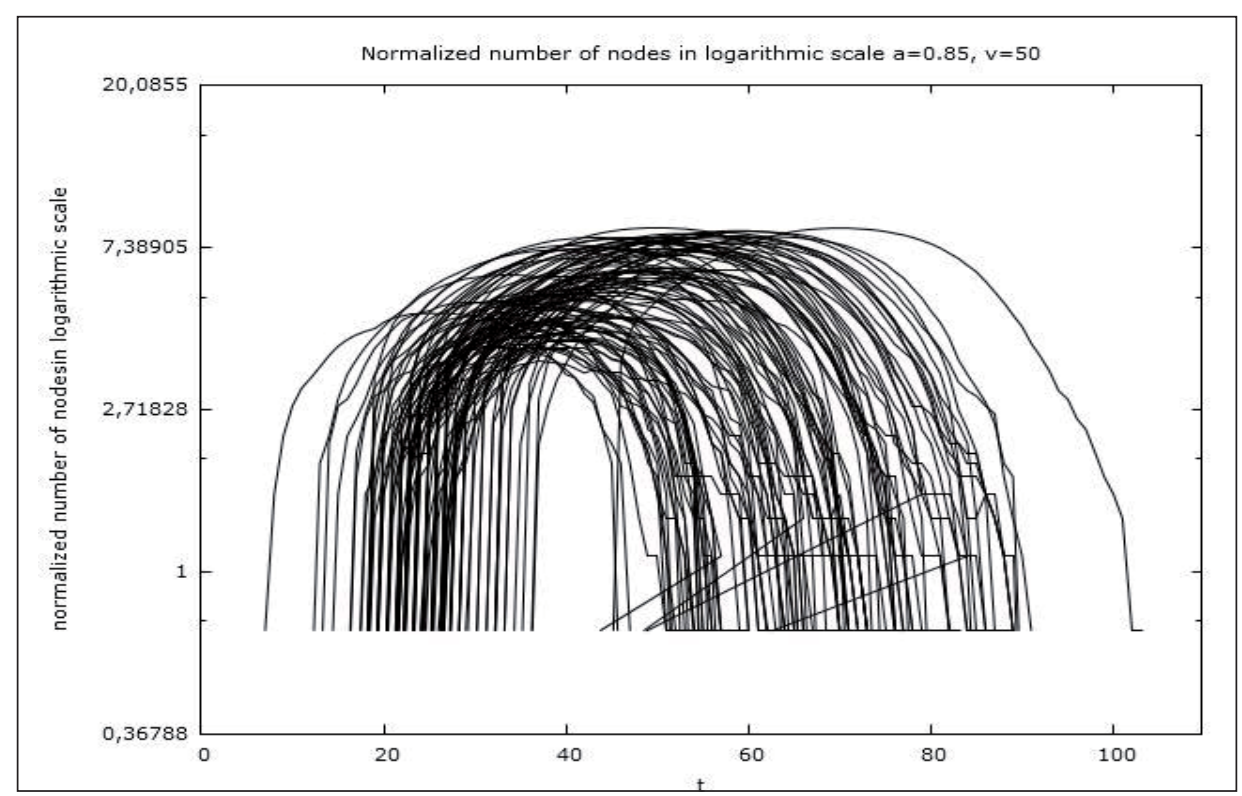

Fig. $4 d$. Trajectories of attractive virus life-cycle performed in 100 local networks Source: own research. 
However, when $\mathrm{v}$ is bigger than 5 , all the nodes inside a local infected network become infected. It is clearly visible when the normalised number of infected nodes is expressed in logarithmic scale (Fig. 4a - 4d). As we have already shown, high attractiveness improves the number of infected nodes that might be considered as sales or contagious people. On the other hand, the parameter v (that represent the length of time when the node is infected) might extend the virus life-cycle. Keeping $v>2$ opens the field for various marketing strategies or pandemic threads and additional costs of promotion or health care because the mean number of infected nodes increases.

In contrast, our model is able to predict trajectories when extremely heavy promotion is associated with unattractive virus or product (Fig. 5). It is visible that the virus life-cycle hardly comes out of the initial country, but the shape of trajectories remains symmetric like the classic product life-cycles (Stark, 2004).

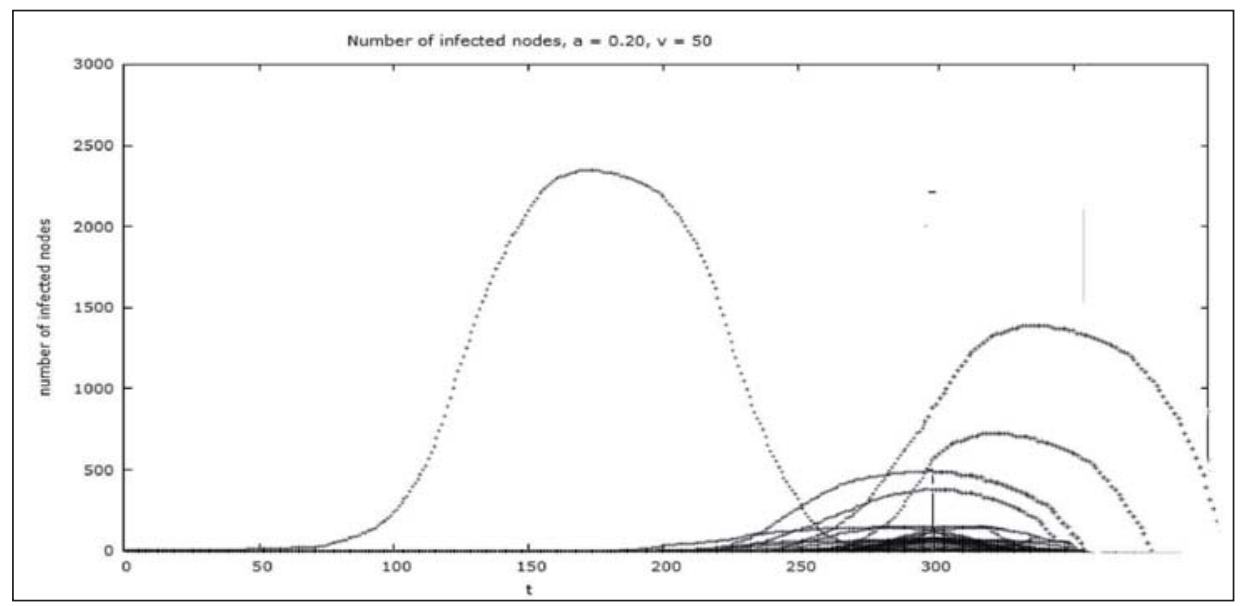

Fig. 5. Trajectories of unattractive virus life-cycle with extremely heavy promotion. Source: own research.

However, it is reasonable to remember that most of possible realisations are not successful (Fig. 1) and in the real world data the optimal marketing strategies or biological weapons tend to increase $\mathrm{v}$ and decrease $\mathrm{v}$ because of financial reasons (costs vs benefits). Therefore, the average trajectories (defined by the mean number of infected nodes in next consecutive steps of simulations performed in 100 realisations of the global network) with high attractiveness (Fig. 6) are so popular.

In our research we have also investigated alternative model where the world as a global network is divided into clusters and global pandemic behaviour happens ocassionally. This divided world has been real til the $20^{\text {th }}$ Century with not well connected global network. However, division into clusters (which will be presented in our future publications in details) may be a recipe for global diseases and in this paper it is worth studying this phenomena of plugging clusters out of global network from individual users point of view. 


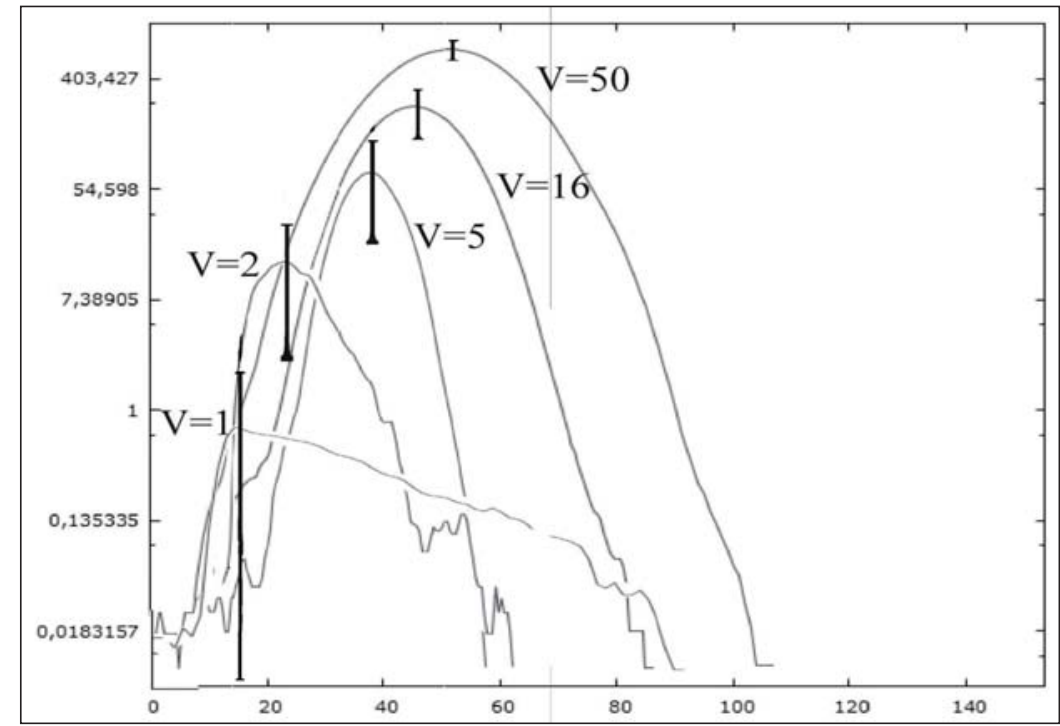

Fig. 6. Trajectories of the average number of infected nodes when $a=1$ in next consecutive steps of simulation.

Source: own research.

\section{INDIVIDUAL USER'S OBSERVATION BY KATARZYNA KUŹMICZ}

I used social media a lot during the pandemic, I had various fan pages on Facebook and also a profile on Instagram. I was posting a lot of content and pictures. I like to write, so I published my thoughts and texts. It was my contact with the world, in addition to face-to-face contacts. It also took up my time, so I would often scroll through the screen after work.

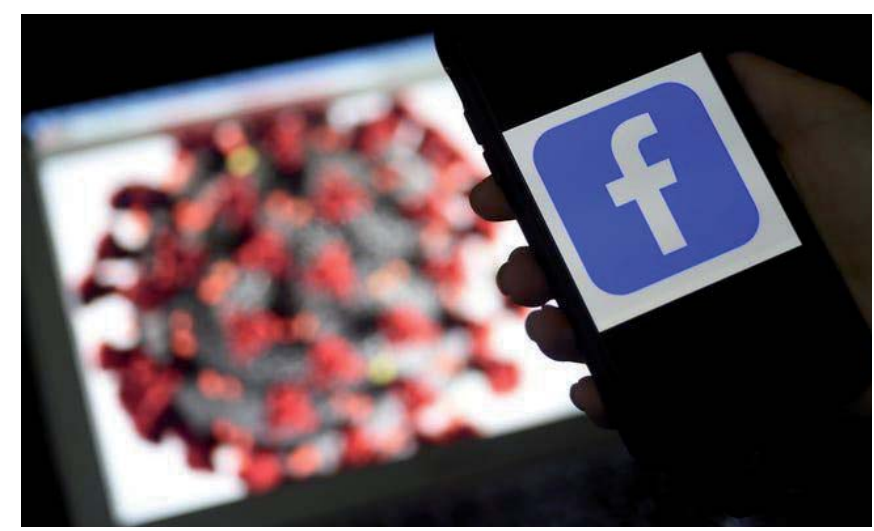

Fig.7. Social media and pandemic spread reveal the same process.

Source: https://www.abc.com.py/tecnologia/2020/04/09/facebook-recurre-a-datos-de-usuarios-paraayudar-a-combatir-el-coronavirus/ 
I am an extroverted and very communicative person, I also participated online in various discussions. My first sense of social media fatigue, came with the women's strikes (November 2020). My friends started sharing certain content. They argued with each other about their views and ideas. Then I felt overwhelmed by their discussions.

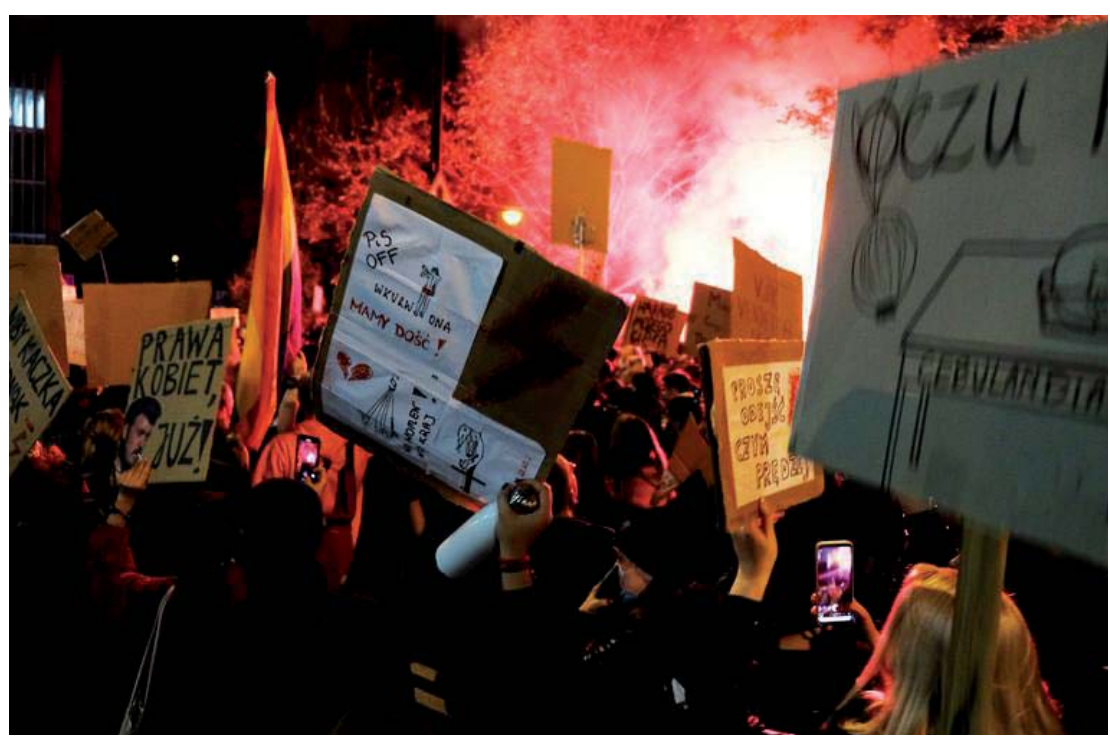

Fig. 8. Riots in Poland in November 2020

Source: https:// wiadomosci.dziennik.pl/polityka/artykuly/7997459,protest-tk-wyrok-aborcja-strajkkobiet-mateusz-morawiecki-internet-koronawirus-zakazenia-epidemia-covid-19.html

Above all, I didn't find myself on either side. I had my own point of view and my own approach to life. I didn't want anyone imposing their thinking on me. Telling me to think the same way. I didn't want to be a part of that. Facebook and my friends' posts were annoing. I decided to deactivate my Facebook account. To opt out of content that I don't want to see anymore.

When I wasn't using Facebook, I realised how much time I spent scrolling through my wall, adding photos, looking for likes or sharing things on groups. I realised that I needed to change my approach if I wanted to have more time for myself.

At some point, I didn't need Facebook anymore. When I went back to Facebook for a while, I was more careful about what I was doing. Where I post, what was on my profile. What I read, what ads are displayed. I started to analyse how much impact Facebook and Instagram and the ads that are displayed could have on my decisions and my choices. I started to see that what I had written, what I liked, what I searched for was connected to social marketing that used to disturb me.

At some point, a movie was recommended to me - The Social Dilemma. This documentary movie was devoted to social media. About what they do to our brains, how they control our emotions and needs. How much they addict us and 
affect our lives. This movie shook me up. What I knew by myself was confirmed and even expanded upon. I could't have imagined that we are under control so much. We make decisions dictated by our statistical choices or needs. I realised that I was addicted to the network- social media. In a way, during the pandemic, I felt better when I shared something, got likes and comments. The emptiness of not having people close to me was rewarded with more posts and likes. It was some contact with the world not direct, but whatever.

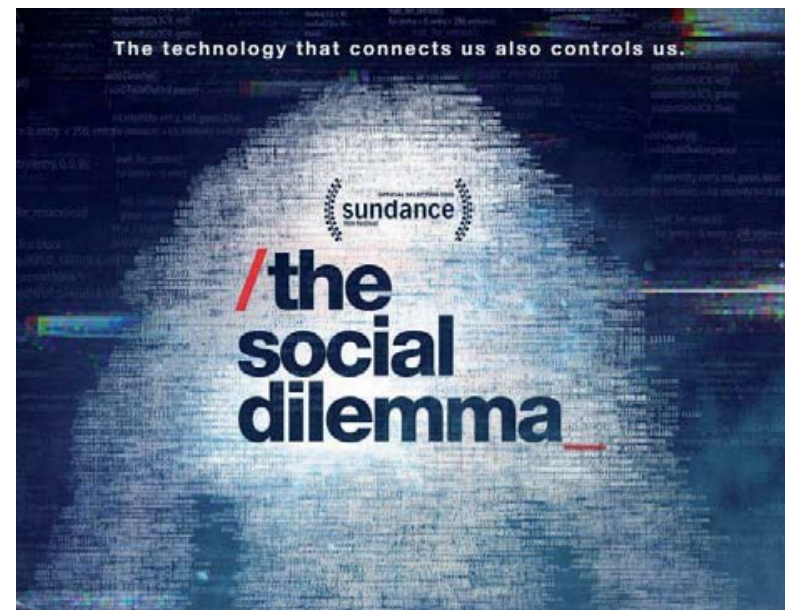

Fig. 9. The Social Dilemma was devoted to changes in contemporary social media.

Source: Screenshot from the movie The Social Dilemma by Jeff Orlowski (2020)

After watching the film, I felt that I wanted to unplug myself from the media. I didn't agree to be controlled and felt spying on the Internet. I decided to delete my Facebook and Instargram accounts. The first two days I spent feeling like an addict without drugs. Lack of focus, irritability. Several times a day I was thinking if I made the right decision. Finally so much of my life was on the Internet. Emotions and desires to look for the latest post and people's coments were had also apeared. However, I stood still in my decisions.

Facebook also gives us time for reconsider our decision and keeps our account frozen. We still have 30 days to delete it permanently. Facebook staff knows perfectly well that there are many people who come back. If they are really addicted they will probably return to the portal. After some 3-4 days I started to see how much spare time I had. My first crash with reality was when I tried to contact my friends. It turned out that I forgot to save all their phone numbers. These people didn't use Telegram or What's Up and Messenger was their only way of communucation. It turned out that it is mandatory at my work to share job advertisements on Facebook. I had to react quickly to this situation and created a fake account that I did not use like before. No private content and no adding friends. I started to be there to publish ads on groups where you could offer a job in the IT industry. Some of my friends I also added to my messenger, because if I didn't communicate with them on messenger then everyday contact would be difficult.

Before the pandemic, I worked in confectionery. I managed to change my job to the IT industry. It was a good decision. If I still worked like people involved in catering I would face permanent lockdown. On the other hand, the IT industry was booming during the pandemic and we started working online. It was a struggle... overwork, too many demands on the employee, focused on results and 
statistics. A lot of client requests for new IT candidates - I worked in recruitment and there was still an employee market in IT. This took a heavy toll on my health and was associated with the beginnings of professional but also social burnout. Although at such a young age - I felt overworked, at the same time used by my employer to work more than possible, for a similar - or even lower - rate, with no benefits, with employee privileges blocked and without creating relationships among employees, only hearing about the constant demands. Therefore I changed my job once again. This time I worked in an international organisation - with one international client. The approach to people was already quite different. Also most of the employees worked in an office, which fostered relationships and prevented social exclusion. My job satisfaction definitely increased. I could also see my friends more often and travel nearby.

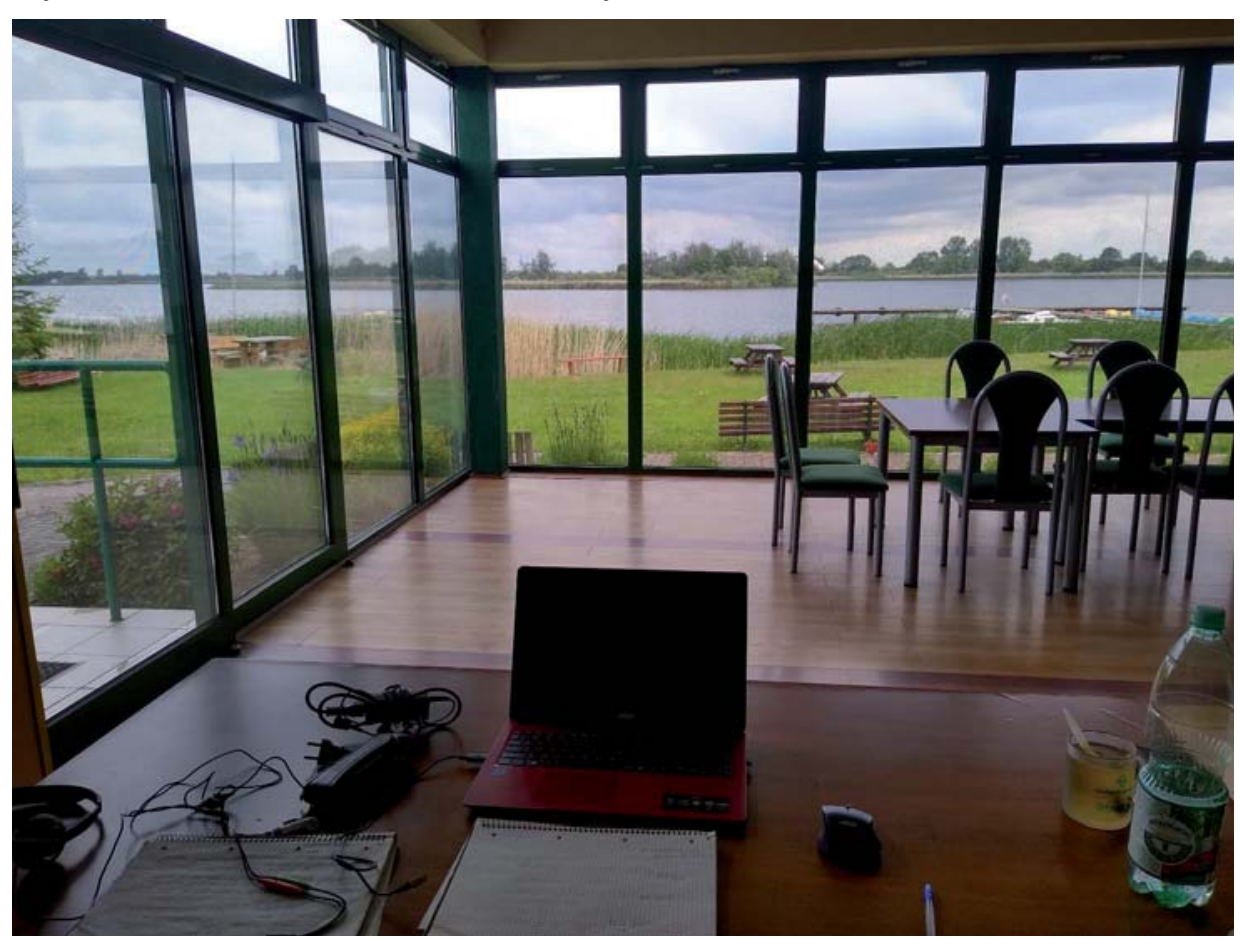

Fig. 10. Working online was no longer stationary, like never before Source: own photo.

I realised that I focused on communication with people only, more than myself. Now I am in contact with my closest people only and we support each other. We spend more time in direct contact now, but also we hang out on the phone or on the webcam. We also try to get together physically more than before. Everyone is tired of the pandemic so we attempt to live as normal as it is possible, we organise birthday parties, bonfires, and meetings. I've certainly saved more time and I'm not so distracted. I also don't see unwanted articles or news. I am also not under 
attack by persistent advertisements, because I avoid spending time online. I focus more on direct communication with people.

Now I concentrate mainly on self-development in the directions I have chosen and direct contact with my friends and family. My world is no longer controlled by machine learning or artificial intelligence. Disconnecting from the network, the media, the general message in a pandemic situation has proven to be for me a healthy approach and a return to normality, regaining faith in a better tomorrow and taking care of my mental and physical health.

\section{Conclusion}

Our model may reflect and predict the reality well in case of well connected global network of the $21^{\text {st }}$ Century Internet era. After introducing simple parameters it is possible to predict product life cycles or pandemic spreads which may affect a single country or the entire world only. Our results are consistent with real data for epidemic and pandemic behaviour and economy or social media as well. These universal trajectories have a long tail represented by contribution from 'laggards'. If the time v (when the node is infected) increases, the shape of trajectories becomes symmetric and reminds the classic shape of product life-cycles.

Our model, however, cannot explain real older cases where in a pre-Internet era only a few countries have been affected. These cases will be analysed in our future publications without global networks but with network divided into clusters. The return to $20^{\text {th }}$ Century pre-Internet era could be a receipe for globalisation which seems to be irreversible. On the other hand, the new alternative solution we propose is selective participation in global network. This direction of dividing or unplugging from the global network may be a receipe for global diseases and the observations given by Katarzyna Kuźmicz in this paper may be an instruction for individual users and self-preservation. Study was partially supported by PNFN (2019-21).

\section{REFERENCES}

[1] Boguna, M., Pastor-Satorras, R. (2020). Epidemic spreading in correlated complex networks. Phys. Rev. E 66, 047104.

[2] Buda, A., Jarynowski, A., \& Kuźmicz, K. (2020). An attempt to unified approach to the evolution of product in the entertainment industry. E-Methodology, 6, 80-93.

[3] Chakraborti, A., Muni Toke, I., Patriarca, M., \& Aberge F. (2011). Econophysics review: II. Agent-based models. Quant. Fin,. 11, 1013-1041.

[4] Dybiec, B. (2009). SIR model of epidemic spread with accumulated exposure. Eur. Phys. J. B 67 377-383.

[5] Edoh, K., MacCarthy, E. (2018). Network and equation-based models in epidemiology. Int. J. Biomath, 11, 1850046.

[6] Epstein, J.M. (1999). Agent-based computational models and generative social science. Complexity, 4, 41-60.

[7] Huang, C., Wang, Y., Li, X., Ren, L., Zhao, J., Hu, Y., Li Z., Fan G., Xu J.,Gu X, Cheng Z,. Yu T., Xia J., Xie X, Yin W., Li H., Liu M., Xiao Y., Gao H., Guo L., Xie J., Wang G., Jiang 
R., Gao Z., Jin Q.,Wang J., \& Bin C.,(2020). Clinical features of patients infected with 2019 novel coronavirus in Wuhan, China“. Lancet, 395(10223), 497-506. doi:10.1016/ S0140-6736(20)30183-5. PMC 7159299. PMID 31986264.

[8] Jarynowski, A., Buda, A., Płatek, D., \& Belik, V. (2020). African Swine Fever Awareness In The Internet Media In Poland - Exploratory Review. E-Methodology, 6, 100-114.

[9] Kephart, J. O., \& White, S. R. (1991). Directed-graph epidemiological models of computer viruses in Proc. 1991 IEEE Computer Society Symposium on Research in Security and Privacy, 343-359.

[10] Kwapień, J.,\& Drożdż, S. (2012). Physics Reports: Physical approach to complex systems. Elsevier, 5015, 116-226.

[11] Moreno, Y., Pastor-Satorras, R.,\& Vespignani, A. (2002). Epidemic outbreaks in complex heterogeneous networks. Eur. Phys. J. B 26, 521-529.

[12] Maxmen A., Mallapaty S. (2021). The COVID lab-leak hypothesis: what scientists do and don't know. Retrieved 25 July, 2020 from https://www.nature.com/articles/ d41586-021-01529-3

[13] Pastor-Satorra,s R., \& Vespignani, A. (2001). Epidemic spreading in scale-free networks. Phys. Rev. Lett, 86, 3200-3203.

[14] Pastor-Satorras R., \& Vespignani, A. (2001). Epidemic dynamics and endemic states in complex network., Phys. Rev. E, 63. 066117.

[15] Reppas, A. I., De Decker, Y., \& Siettos, C. I. (2012). On the efficiency of the equation-free closure of statistical moments: dynamical properties of a stochastic epidemic model on Erd"os-R'nyi networks. J. Stat. Mech, P02020.

[16] Sadedin, S.,Dybiec, B.,\& Briscoe, G. (2003). A toy model of faith-based systems evolution. Physica, A 323, 715-725.

[17] Samanidou, E., Zschischang, E., Stauffer, D., \& Lux, T. (2007). Agent-based models of financial markets. Rep. Prog. Phys, 70, 409-450.

[18] Stark, J. (2004). Product Lifecycle Management: 21st Century Paradigm for Product Realisation. Hamburg: Springer.

[19] Trpevski, D., Tang, W. K. S., \& Kocarevm L. (2010). Model for rumor spreading in networks. Phys. Rev., E 81, 056102. 